\title{
The Role of Skin and Muscle Resistance Vessels \\ in Reflexes Mediated by the Baroreceptor System
}

\author{
G. David Beiser, Robert Zeuis, Stephen E. Epstein, Dean T. Mason, and \\ EUgene Braunwald
}

From the Cardiology Branch, National Heart Institute, Bethesda, Maryland 20014

A BSTRACT The role of skin and muscle vascular beds in baroreceptor-mediated alterations of peripheral vascular resistance was evaluated in six normal subjects in whom the skin circulation in one forearm was temporarily suppressed by epinephrine iontophoresis. Baroreceptor activity was enhanced by application of negative pressure to the neck (neck suction) and inhibited by application of lower body negative pressure. Forearm blood flow was measured simultaneously in both arms with strain gauge plethysmographs. Since blood flow in the treated arm consisted entirely of muscle flow, skin flow was calculated from the difference between total forearm flow in the intact arm and muscle flow in the treated arm. Vascular resistances were calculated as the ratio of mean arterial pressure to the blood flow of each vascular bed. During neck suction, mean arterial pressure decreased from an average of 89 to $75 \mathrm{~mm}$ of $\mathrm{Hg}(P<0.005)$, heart rate decreased from an average of 60 to 55 beats $/ \mathrm{min}(P<0.005)$, and total skin and muscle flows remained essentially unchanged. Cutaneous vascular resistance decreased from an average of 75 to $49 \mathrm{~mm}$ of $\mathrm{Hg} / \mathrm{ml}$ per $100 \mathrm{~g}$ per min $(P<0.05)$, muscle vascular resistance from 68 to $51(P<0.005)$, and total forearm vascular resistance from 36 to 24 ( $P<$ 0.025 ). During lower body negative pressure, heart rate increased from an average of 59 to 69 beats $/ \mathrm{min}(P<$ $0.005)$, mean arterial pressure did not change significantly, and significant decreases occurred in forearm blood flow from 5.4 to $2.7 \mathrm{ml} / 100 \mathrm{~g}$ per min, in skin blood flow from 3.1 to 1.4 , and in muscle blood flow from 2.3 to 1.3 . Cutaneous vascular resistance increased from an average of 47 to $110 \mathrm{~mm}$ of $\mathrm{Hg} / \mathrm{ml}$ per $100 \mathrm{~g}$ per $\min (P<0.05)$, muscle vascular resistance from 43 to $72(P<0.005)$, and total forearm vascular resistance from 20 to $38(P<0.001)$. These results demonstrate

Received for publication 16 June 1969 and in revised form 22 August 1969. that both the skin and muscle resistance vessels participate in reflex changes initiated by alterations in baroreceptor activity.

\section{INTRODUCTION}

It is well known that changes in peripheral vascular resistance occur as a result of reflexes mediated by the baroreceptor system (1-9). Since a considerable proportion of the total cardiac output is directed through blood vessels supplying skeletal muscle and skin (10), the resistance vessels in these tissues could play an important role in the regulation of arterial pressure. The present investigation served two major purposes. The first was to determine if the skin vessels, the muscle vessels, or both participate in baroreceptor-mediated reflexes. This problem has never been adequately evaluated for the reason that in all previous investigations changes in vascular resistance were inferred from such indirect evidence as changes in skin temperature, differences in blood flow in the hand vs. that of the forearm or calf, or alterations in the oxygen saturation of blood from forearm veins (11-16). The lack of precision in these studies is further suggested by the conflicting results reported. The second major purpose was to determine the effects on skin and muscle blood vessels of stimulating the arterial baroreceptors located in the carotid sinus independently of any effects accruing from stimulating the low pressure baroreceptors (located in the great veins and atria). Previous investigations have been performed using interventions such as the application of subatmospheric pressure to the lower body, tilt, or intrathoracic pressure changes, all of which probably influence the low as well as the high pressure baroreceptors.

In the present study separation of limb blood flow into its cutaneous and muscular components was obtained by suppression of the cutaneous circulation of one forearm 
by epinephrine iontophoresis (17) and by comparing its blood flow with that of the opposite intact forearm.

\section{METHODS}

Investigations were performed in six healthy male subjects whose ages ranged from 19 to $23 \mathrm{yr}$. The subjects were studied in a basal postabsorptive state at a room temperature of $25^{\circ} \mathrm{C}$. All studies were performed with the patients in the supine position. Intra-arterial pressure was recorded through a short polyvinyl catheter introduced percutaneously into the radial artery with zero pressure set at the level of the midthorax. Forearm blood flow was measured by the acute venous occlusion technique using a single-strand mercury-in-rubber strain gauge plethysmograph (18). $1 \mathrm{~min}$ after the hand was excluded from the circulation by the inflation of a wrist cuff above systolic blood pressure, a brachial cuff was rapidly inflated to $30 \mathrm{~mm}$ of $\mathrm{Hg}$ and forearm blood flow, expressed in milliliters $/ 100$ grams per minute, was calculated from the rate of change of forearm circumference during venous occlusion. With the radial arterial catheter in position, several simultaneous determinations of forearm blood flow in both arms were made before the application of epinephrine iontophoresis in order to insure that flows were equal bilaterally. This was achieved in all subjects by placing both mercury-in-rubber strain gauges at identical midforearm positions and by carefully adjusting the height and angle of each arm relative to the trunk.

Epinephrine iontophoresis was then applied to one arm by the technique of Cooper, Edholm, and Mottram (19), as modified by Collins and Ludbrook $(20)$. The procedure consisted of wrapping the thoroughly cleansed arm in a gauze bandage soaked with epinephrine hydrochloride $1: 2000(\mathrm{pH}$ 4.5). The gauze was covered with aluminum foil that served as the positive electrode and was secured by an elastic bandage. The leg served as the negative electrode and was similarly wrapped except that saline replaced the epinephrine solution. Iontophoresis was performed with a current of $20 \mathrm{ma}$ applied for $20 \mathrm{~min}$. This technique effectively depresses cutaneous blood flow as demonstrated in a previous study in which this technique was employed. In the previous study body heating caused forearm blood flow in the control forearm to increase reflexly by $81 \%$ in contrast to only an $8 \%$ increase in the epinephrine-treated $\operatorname{arm}(17)$.

Since iontophoresis suppressed cutaneous blood flow nearly completely, forearm blood flow in the treated arm was considered to consist of muscle blood flow only. Skin flow was derived as the difference between total forearm blood flow of the control arm and muscle blood flow of the opposite treated arm. Forearm vascular resistance in millimeters of $\mathrm{Hg} /$ milliliter per 100 grams per minute was calculated from the ratio of mean arterial pressure to forearm blood flow. The individual resistances of the cutaneous and muscular vascular beds were calculated in a similar fashion.

Baroreceptor activity was modified by the following two methods. (a) The carotid arterial baroreceptors were stimulated by the application of negative pressure to the neck $(7,21)$. This was accomplished by enclosing the neck in a Plexiglas box from the upper thorax to the level of the mandible and the base of the occipital bone and creating a subatmospheric pressure of $50 \mathrm{~mm}$ of $\mathrm{Hg}$ within $10 \mathrm{sec}$. This intervention increases transmural pressure across the carotid arteries and thereby stimulates the baroreceptors located in the carotid sinus. (b) The baroreceptors were inhibited by the application of lower body negative pressure. This was accomplished by placing the lower part of the body from the level of the iliac crests into an airtight box $(5,6,22,23)$ and decreasing pressure within it to $60 \mathrm{~mm}$ of $\mathrm{Hg}$ below ambient atmospheric pressure. This level of negative pressure was achieved within $30 \mathrm{sec}$.

After completion of epinephrine iontophoresis, each subject underwent four separate applications of neck suction lasting $2 \mathrm{~min}$ each. Heart rate and mean arterial pressure were recorded continuously, and five to seven determinations of forearm blood flow were made simultaneously in both arms before, during, and shortly after each intervention. After return to the control state, the subjects were then studied in an identical fashion during two periods of lower body negative pressure lasting $3 \mathrm{~min}$ each. Epinephrine iontophoresis has been shown to remain effective for at least $1 \mathrm{hr}$ (24) and the entire study was completed within that period of time.

All data obtained during the control and intervention periods were averaged for each individual subject. These values were then used to determine the means for the entire group. A paired $t$ test was employed for all statistical calculations.

\section{RESULTS}

Effects of subatmospheric pressure applied to the neck

Data calculated from one subject during two consecutive periods of negative pressure applied to the neck are illustrated in Fig. $1 \mathrm{~A}$. A summary of the effects of neck suction in all of the subjects is shown in Fig. $2 \mathrm{~A}$, and the original recordings obtained in one subject are reproduced in Fig. $3 \mathrm{~A}$.

Heart rate and arterial pressure. The application of $50 \mathrm{~mm}$ of $\mathrm{Hg}$ subatmospheric pressure to the neck produced a rapid and sustained reduction in both heart rate and blood pressure in all subjects. Heart rate decreased an average of $5 \pm 0.8$ beats $/ \mathrm{min}$ (SEM difference) or $9 \%$ of control values $(P<0.005)$ and mean arterial pressure fell an average of $13.7 \pm 2.3 \mathrm{~mm}$ of $\mathrm{Hg}$ or $15 \%$ $(P<0.005)$.

Forearm blood flow. Total forearm blood flow in the control arm, muscle blood flow in the arm with epinephrine iontophoresis, and the derived value for skin flow did not change significantly during neck suction.

Forearm vascular resistance. Neck suction caused significant reductions in total forearm vascular resistance (averaging $12 \pm 3.7 \mathrm{~mm}$ of $\mathrm{Hg} / \mathrm{ml}$ per $100 \mathrm{~g}$ per min or $33 \%$ of control values, $P<0.025)$, in muscular resistance (averaging $17 \pm 3.5$ or $25 \%, P<0.005$ ), and in cutaneous vascular resistance (averaging $26 \pm 9.9$ or $35 \%, P<0.05)$. Thus, an increase in the transmural pressure of the carotid sinus resulted in reflex dilatation of the resistance vessels in both skin and muscle.

\section{Effects of lower body negative pressure}

The circulatory effects in one subject of two consecutive episodes of lower body negative pressure are 
shown in Fig. $1 \mathrm{~B}$. The results in all six subjects are summarized in Fig. $2 \mathrm{~B}$, and the original recordings obtained in one subject are reproduced in Fig. $3 \mathrm{~B}$.

Heart rate and arterial pressure. The application of $60 \mathrm{~mm}$ of $\mathrm{Hg}$ subatmospheric pressure to the lower body resulted in an average increase in heart rate of $10 \pm 1.5$ beats/min or $16 \%$ of control $(P<0.005)$. No significant change occurred in mean arterial pressure.

Forearm blood flow. During lower body negative pressure total forearm blood flow decreased an average of $2.72 \pm 0.4 \mathrm{ml} / 100 \mathrm{~g}$ per min or $51 \%$ of control $(P<$ $0.005)$, muscle flow decreased by $0.98 \pm 0.2$ or $43 \%(P<$ $0.01)$, and skin flow decreased by $1.70 \pm 0.4$ or $56 \%(P<$ $0.02)$.

Forearm vascular resistance. Lower body negative pressure caused significant increases in total forearm vascular resistance (averaging $18 \pm 2.3 \mathrm{~mm}$ of $\mathrm{Hg} / \mathrm{ml}$ per $100 \mathrm{~g}$ per $\min$ or $86 \%, P<0.001$ ), in muscular vascular resistance (averaging $29 \pm 5.5$ or $67 \%, P<$ 0.005 ), and in cutaneous vascular resistance (averaging $63 \pm 21$ or $136 \%, P<0.05)$. Thus, lower body negative pressure produced significant reflex constriction in both cutaneous and muscular resistance vessels.

\section{DISCUSSION}

Reflex regulation of the resistance vessels by the carotid sinus baroreceptors was first demonstrated in the dog by Heymans, Bouckaert, and Dautrebande (1) and Rein (2) in 1931. Although initial studies in man suggested that changes in peripheral vascular resistance did not occur as a result of reflexes mediated by baroreceptors located in the arterial system (14-16, 21), recent investigations have shown that mechanical stimulation of the carotid sinus stretch receptors by neck suction (7) and electrical stimulation of the carotid sinus nerves $(4,8,9)$ produce significant decreases in forearm and total peripheral vascular resistance.

In contrast, interventions that cause inhibition of baroreceptor activity in man lead to reflex vasoconstriction. Thus, constriction of the resistance vessels occurs during both head-up tilt $(3,6)$ and the application of negative pressure to the lower body $(5,6,23)$. That the
A

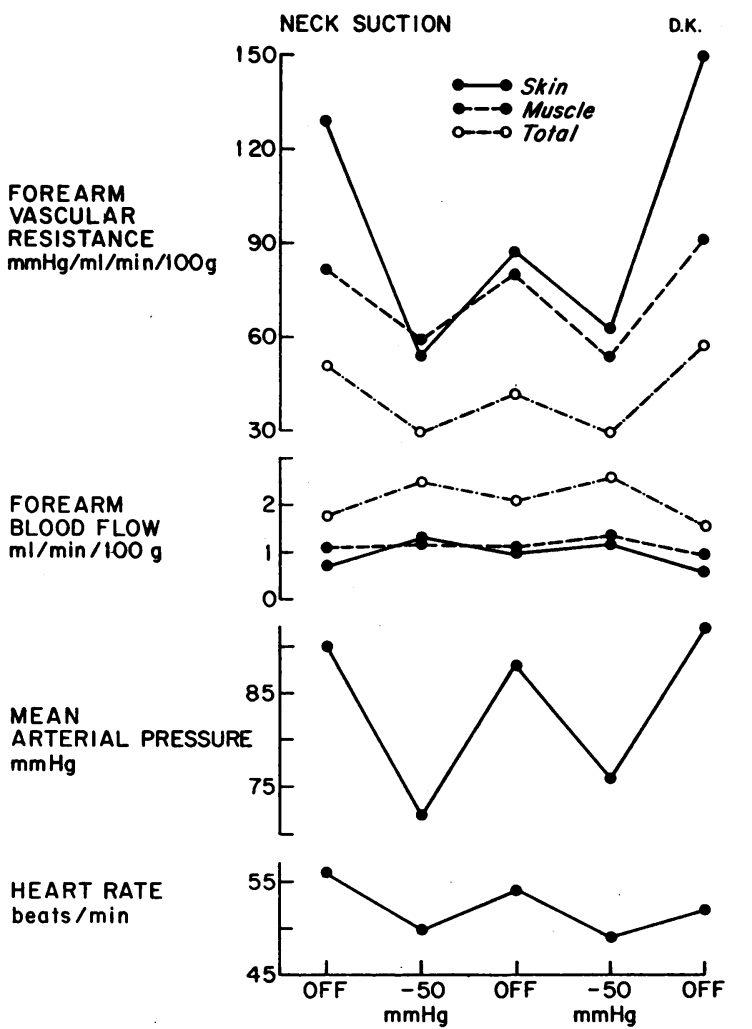

$B$

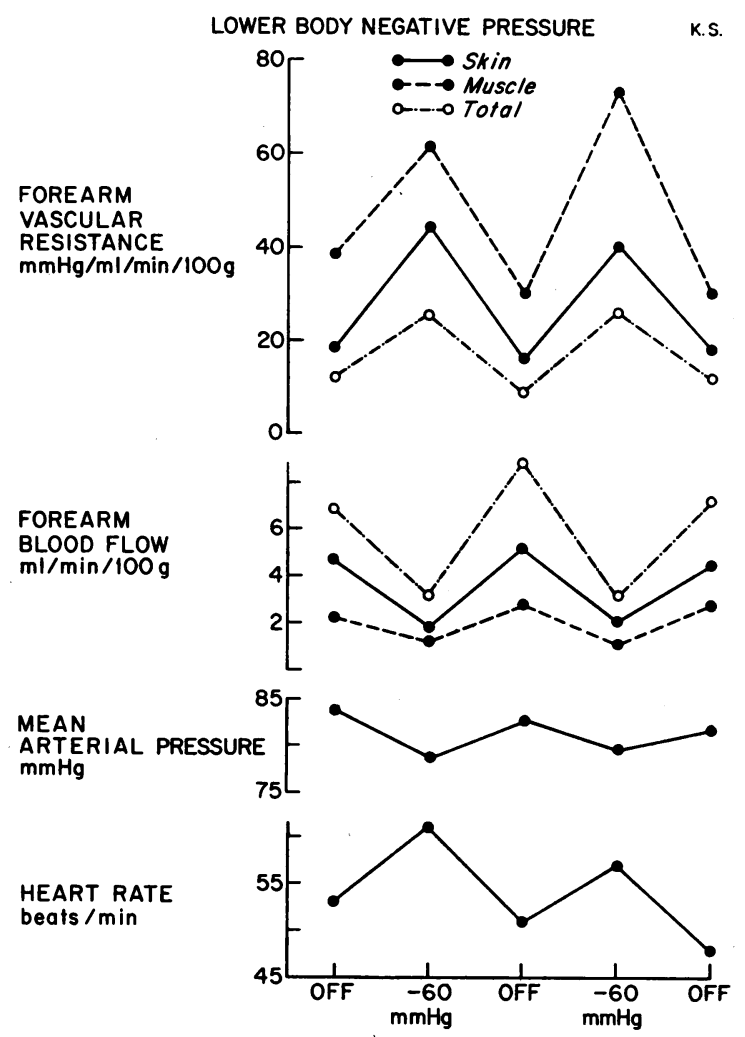

Figure 1 The effects in a single subject of two consecutive periods of neck suction (A) and in another subject of two consecutive periods of lower body negative pressure (B) on total, muscle, and skin vascular resistance and blood flow and on mean arterial pressure and heart rate. Each point represents the mean value for all determinations made during each control and intervention period. 

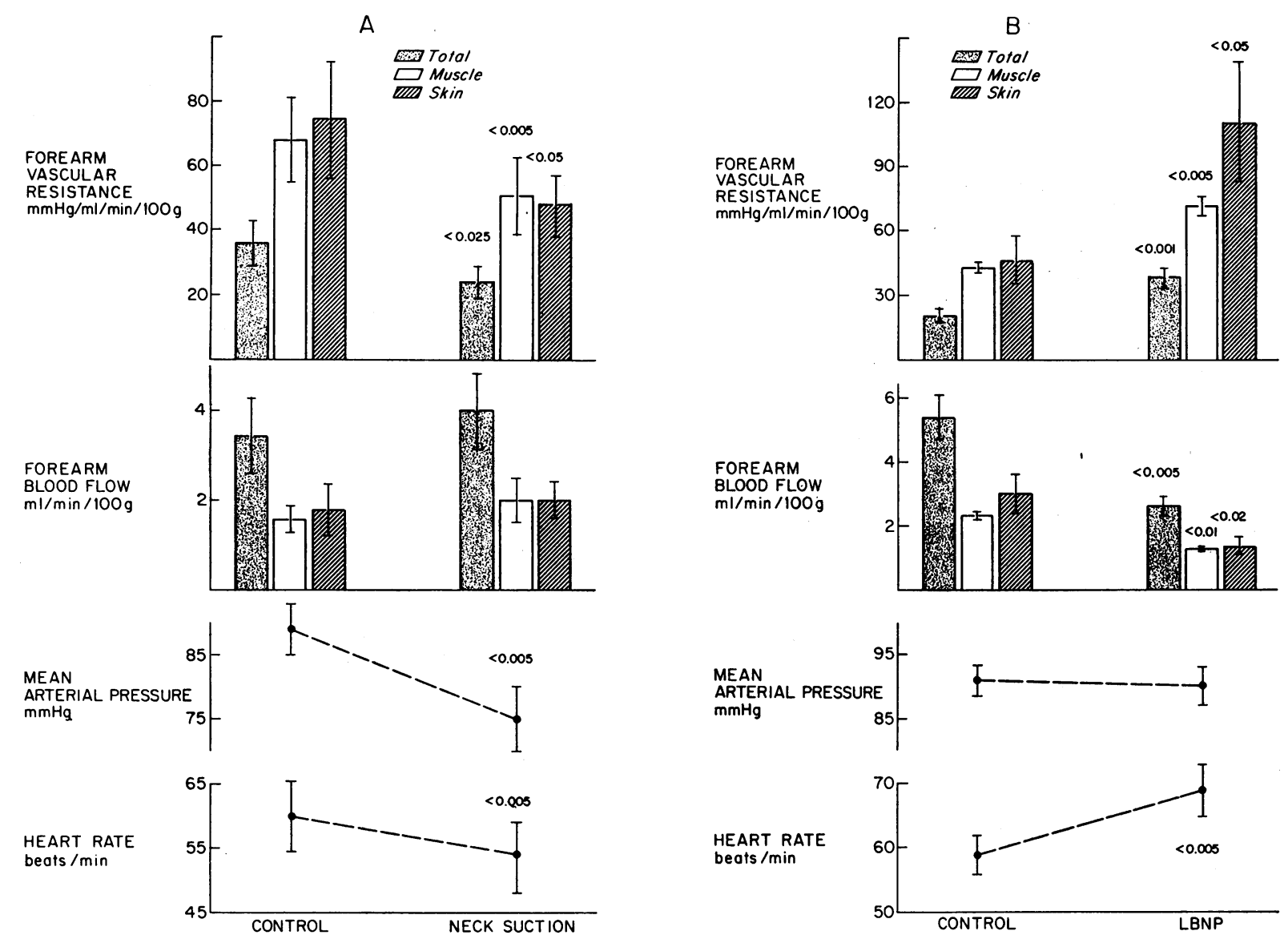

FIGURE 2 The results of neck suction (A) and of lower body negative pressure (B). Each column or closed circle represents the mean value for the data of all the subjects. Standard error of the mean are shown by the small vertical bars. Significance ( $P$ values) is shown only when differences between data from the control and intervention periods are significant at the 0.05 level or greater.

mean arterial pressure usually decreases only minimally during either of these interventions attests to the effectiveness of baroreceptor mediated reflexes in the maintenance of arterial pressure.

While it is thus apparent that both head-up tilt and lower body negative pressure cause circulatory changes that lead to compensatory reflexes mediated by the baroreceptors, it is not clear whether these reflexes originate from baroreceptors located in the low pressure system (great veins or atria), in the high pressure system (carotid sinus and aortic arch), or both. The relative roles of each of these systems in producing the reflex changes observed during head-up tilt or lower body negative pressure would be difficult to assess since both of these interventions cause peripheral pooling of blood; this reduces atrial pressure and volume, a change that could affect low pressure receptors. However, the consequent decrease in ventricular filling also lowers cardiac output and thereby lowers pulse pressure, a change that has been shown to have a considerable effect on the activity of the high pressure receptors even in the absence of any change in the mean arterial pressure (25). Indeed as exemplified by the recordings shown in Fig. $3 \mathrm{~B}$, a decrease in pulse pressure occurred in all of the subjects during the application of subatmospheric pressure to the lower body. Moreover, the substantial increase in heart rate after lower body negative pressure strongly suggests that the reflex originated from the arterial baroreceptors since cardiac slowing would be expected if the reflex originated from the low pressure receptors (26). The fact that vasodilatation occurs when the high pressure baroreceptors are stimulated preferentially by the application of subatmospheric pressure to the neck (7) or by electrical stimulation of the carotid sinus nerves $(4,8,9)$ indicates that these receptors certainly play an important role in the alterations of 
vascular resistance induced by baroreceptor-mediated reflexes.

Although changes in peripheral vascular resistance are clearly an important part of the efferent arm of reflexes mediated by the baroreceptor system, the major findings of the present investigation relate to the relative roles of the vessels of the skin and muscle in these reflexes. The results of previous studies assessing the degree of participation of the cutaneous and muscular resistance vessels in baroreceptor-mediated reflexes have been conflicting. For example, a decrease in skin temperature after the assumption of the erect position was interpreted by several investigators as indirect evidence of reflex cutaneous vasoconstriction (11-13). However, it could be argued that a decrease in cutaneous blood flow and hence temperature could have resulted solely from

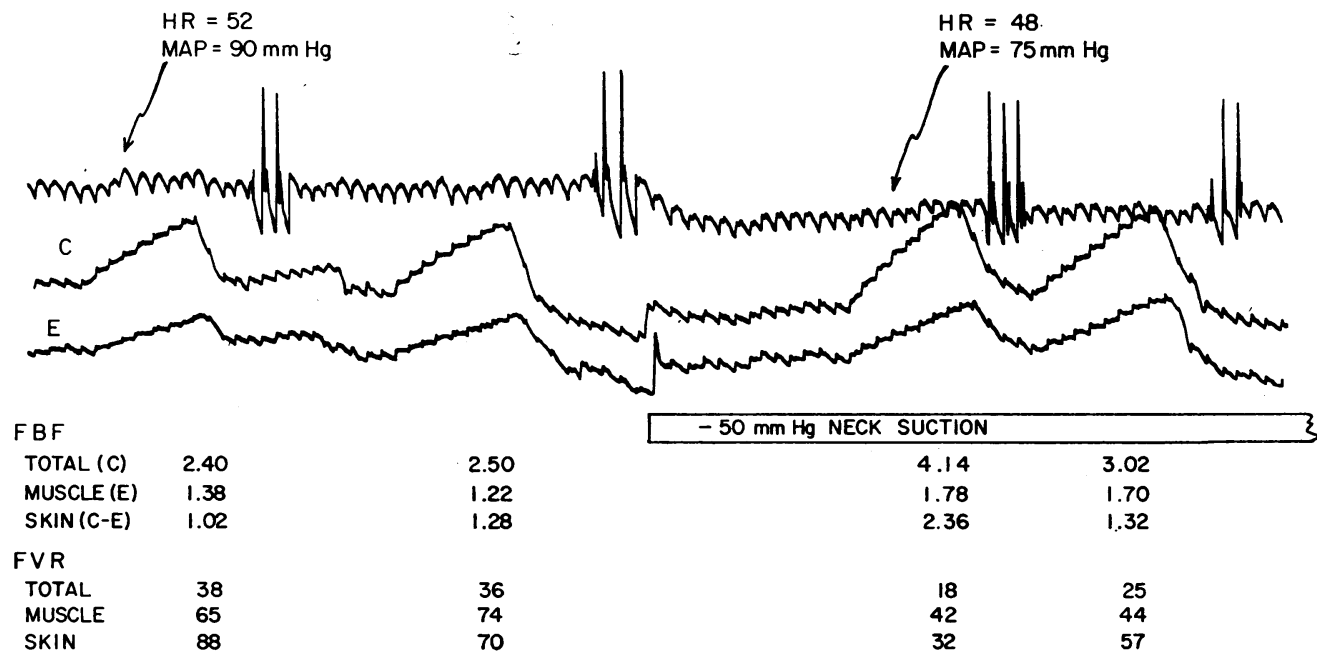

B

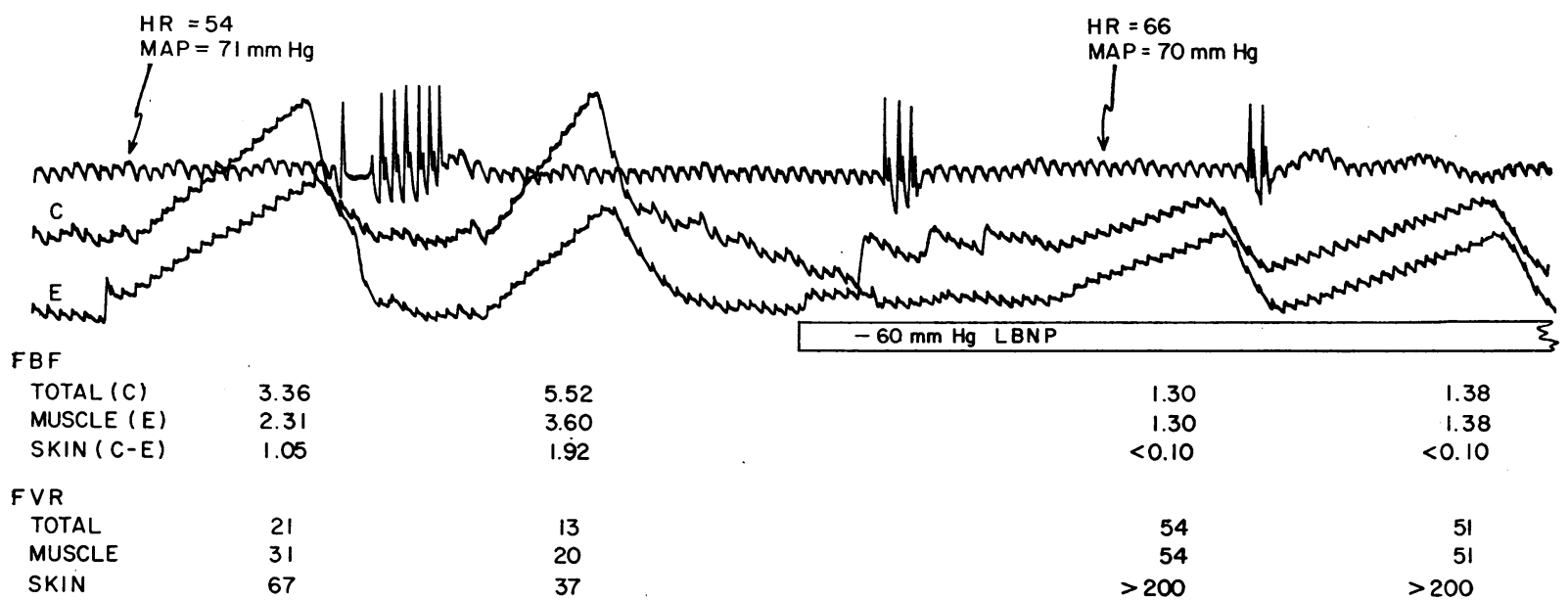

FIGURE 3 Recordings obtained in two different subjects (A and $B$ ) of mean arterial pressure (MAP) and plethysmographic tracings of forearm blood flow (FBF) immediately before and after the onset of neck suction in A and lower body negative pressure (LBNP) in B. Shown beneath the recordings are calculated values for each determination of total forearm flow in the control arm (C), muscle flow in the arm treated with epinephrine iontophoresis (E), and the derived value for skin flow (C-E). Vascular resistances (FVR) for each component of forearm circulation are also given. $H R=$ heart rate. 
an associated decrease in cardiac output in the absence of any cutaneous vasoconstriction. On the other hand when changes in skin circulation were inferred from changes in the oxygen saturation of superficial forearm veins or from changes in blood flow in the hand compared to the more muscular forearm or calf, no apparent alteration occurred in the cutaneous vessels in response to leg raising (14) or changes in intrathoracic pressure (16). It should also be noted that in all of these investigations only interventions affecting both the high and low pressure baroreceptors were employed and the effects of changes in arterial baroreceptor activity alone were not evaluated.

In contrast, the results of the present investigation clearly demonstrate that in the human forearm the resistance vessels of both skin and muscle respond to reflexes occurring when the stimulus input to the arterial baroreceptors is altered alone or in combination with that to the low pressure baroreceptors. Thus, stimulation of arterial baroreceptors in the carotid sinus by negative pressure applied to the neck produces reflex dilatation of both cutaneous and muscular resistance vessels; and conversely, inhibition of activity in both the high and low pressure baroreceptors by lower body negative pressure results in reflex constriction of these same vessels.

The reasons for the discrepancy between the findings of the present investigation and the previously cited studies deserve consideration. It is possible that the method for estimating directional changes in skin blood flow from alterations of oxygen saturation of blood obtained from veins believed to drain the skin may not be valid under all circumstances. For example if reflex vasodilatation is accompanied by the opening of arteriovenous shunts between muscle and skin vessels, contamination of cutaneous venous blood by blood-draining muscle beds may mask the reflex vasodilatation that may have occurred in the cutaneous vessels. Lack of participation of skin vessels in baroreceptor-mediated reflexes also has been inferred from the lack of consistent changes in hand blood flow observed in response to various interventions affecting baroreceptor activity. However, it is possible that the inability to demonstrate consistent reflex changes in hand flow may have been due to the marked spontaneous fluctuation in flow often seen in the hand (16). More importantly, it is not at all clear if the hand is truly representative of the cutaneous circulation. In addition when interventions such as the Valsalva maneuver (16) are employed that produce large and rapidly changing levels of arterial pressure, measurement of forearm or hand flow alone, without measurement of arterial pressure, may lead to erroneous conclusions about alterations in vascular resistance.
The validity of the findings in the present investigation depends upon the effectiveness of epinephrine iontophoresis to suppress the skin circulation without affecting the underlying muscle circulation. Evidence that iontophoresis produces nearly complete suppression of skin blood flow has been demonstrated by both Edholm, Fox, and Macpherson (24) and Zelis and Mason (17). Both of these groups observed that when large reflex increases in blood flow occur in the untreated forearm during body warming, very little or no increase occurs in the treated forearm. Moreover, the finding (24) that forearm blood flow increases to the same extent in the control and treated forearms after standard hand-gripping exercises suggests that epinephrine iontophoresis does not appreciably affect the muscular resistance vessels. Thus on the basis of the findings of this investigation, we conclude that the resistance vessels of both the skin and muscle participate in the homeostatic reflexes mediated by the baroreceptor system.

\section{ACKNOWLEDGMENTS}

We wish to express our appreciation to Mrs. Mimi Winterhalter and to Miss Isabelle Ambrose for their valuable technical assistance, and to Dr. John T. Shepherd, who kindly provided plans for construction of the lower body negative pressure box and negative pressure neck box.

\section{REFERENCES}

1. Heymans, C., J. J. Bouckaert, and L. Dautrebande. 1931. Sur la regulation reflexe de la circulation par les nerfs vasosensibles du sinus carotidien. Arch. Intern. Pharmacodyn. 40: 292.

2. Rein, H. 1931. Vasomotorische Regulationen. Ergebn. Physiol. 32: 28.

3. Brigden, W., S. Hoxwarth, and E. P. Sharpey-Schafer. 1950. Postural changes in the peripheral blood-flow of normal subjects with observations on vasovagal fainting reactions as a result of tilting, the lordotic posture, pregnancy and spinal anesthesia. Clin. Sci. 9: 79.

4. Carlsten, A., B. Folkow, G. Grimby, C. -A. Hamberger, and O. Thulesius. 1958. Cardiovascular effects of direct stimulation of the carotid sinus nerve in man. Acta Physiol. Scand. 44: 138.

5. Stevens, P. M., and L. E. Lamb. 1965. Effects of lower body negative pressure on the cardiovascular system. Amer. J. Cardiol. 16: 506.

6. Gilbert, C. A., and P. M. Stevens. 1966. Forearm vascular responses to lower body negative pressure and orthostasis. J. Appl. Physiol. 21: 1265.

7. Bevegard, B. S., and J. T. Shepherd. 1966. Circulatory effects of stimulating the carotid arterial stretch receptors in man at rest and during exercise. J. Clin. Invest. 45: 132 .

8. Tuckman, J. 1968. Electrical stimulation of the sinus nerves in hypertensive patients: clinical evaluation of physiological studies. In Neural Control of Arterial Pressure. J. E. Wood, editor. American Heart Association Inc., New York. 23-38.

9. Epstein, S. E., G. D. Beiser, R. E. Goldstein, M. Stampfer, G. Glick, A. S. Wechsler, and E. Braunwald. 1969. 
Circulatory effects of electrical stimulation of the carotid sinus nerves in man. Circulation. 40: 269.

10. Wade, O. L., and J. M. Bishop. 1962. Cardiac Output and Regional Blood Flow. Blackwell Scientific Publications Ltd., Oxford.

11. Youmans, J. B., J. H. Akeroyd, and H. Frank. 1935. Changes in the blood and circulation with changes in posture. The effect of exercise and vasodilatation. J. Clin. Invest. 14: 739.

12. Mayerson, H. S., and L. A. Toth. 1939. The influence of posture on skin and cutaneous temperatures. Amer. J. Physiol. 125 : 474.

13. Nielsen, M., L. P. Herrington, and C. -E. A. Winslow 1939. The effect of posture upon peripheral circulation. Amer. J. Physiol. $127: 573$.

14. Roddie, I. C., and J. T. Shepherd. 1956. The reflex nervous control of human skeletal muscle blood vessels. Clin. Sci. 15: 433.

15. Roddie, I. C., and J. T. Shepherd. 1957. The effects of carotid artery compression in man with special reference to changes in vascular resistance in the limbs. $J$. Physiol. (London). 139: 377.

16. Roddie, I. C., J. T. Shepherd, and R. F. Whelan. 1958. Reflex changes in human skeletal muscle blood flow associated with intrathoracic pressure changes. Circ. Res. 6: 232.

17. Zelis, R., D. T. Mason, and E. Braunwald. 1969. The partition of blood flow to the cutaneous and muscular beds of the forearm at rest and during leg exercise in normal subjects and in patients with heart failure. Circ. Res. 24: 799.
18. Zelis, R., D. T. Mason, and E. Braunwald. 1968. A comparison of the effects of vasodilator stimuli on peripheral resistance vessels in normal subjects and in patients with congestive heart failure. J. Clin. Invest. 47: 960 .

19. Cooper, K. E., O. G. Edholm, and R. F. Mottram. 1955. The blood flow in skin and muscle of the human forearm. J. Physiol. (London). 128: 258.

20. Collins, G. M., and J. Ludbrook. 1967. Behavior of vascular beds in the human upper limb at low perfusion pressure. Circ. Res. 21: 319.

21. Ernsting, J., and D. J. Parry. 1957. Some observations on the effects of stimulating the stretch receptors in the carotid artery of man. J. Physiol. (London). 137: 45. (Abstr.)

22. Samueloff, S. L., N. L. Browse, and J. T. Shepherd. 1966. Response of capacity vessels in human limbs to head-up tilt and suction on the lower body. J. Appl. Physiol. 21: 47.

23. Epstein, S. E., G. D. Beiser, M. Stampfer, and E. Braunwald. 1968. Role of the venous system in baroreceptormediated reflexes in man. J. Clin. Invest. $47: 139$.

24. Edholm, O. G., R. H. Fox, and R. K. Macpherson. 1956. The effect of body heating on the circulation in skin and muscle. J. Physiol. (London). 134: 612.

25. Ead, H. W., J. H. Green, and E. Neil. 1952. A comparison of the effects of pulsatile and non-pulsatile blood flow through the carotid sinus on the reflexogenic activity of the sinus baroreceptors in the cat. J. Physiol. (London). 118: 509.

26. Bainbridge, F. A. 1915. The influence of venous filling upon the rate of the heart. J. Physiol. (London). 50: 65. 